\title{
System approach to operating transport structures geodynamic safety estimation
}

\author{
Natalia Bykova ${ }^{1, *}$, Andrey Yashnov $^{2}$, Rudolf Semenov ${ }^{1}$ \\ ${ }^{1}$ Irkutsk State Transport University, Chernyshevskogo st., 15, Irkutsk, 664074, Russia \\ ${ }^{2}$ Siberian State Transport University, ul. Dusi Kovalchuk, 191, Novosibirsk, 630049, Russia
}

\begin{abstract}
The paper describes a system approach to operating transport structures geodynamic safety estimation and diagnostic methods for bridges in order to determine the parameters of geodynamic safety.
\end{abstract}

\section{Introduction}

Extensive transport facilities (ETF), including railways, stretch for many thousands of kilometers, crossing the territories with different geodynamic activity. The constructions of transport structures, as a rule, are designed for a long service life and the cost effectiveness for eliminating the consequences of geodynamic influences largely depends on the correct system approach to studying geodynamic processes and protecting artificial engineering structures from them. This article outlines a systematic approach to covering the main aspects of this problem.

\section{Types of geodynamics and their accounting in the transport facilities design}

The cause of the Earth crust geodynamics are independent and interrelated structural parts movements of endogenous and exogenous nature. Modern concepts of tectonics for interplate boundaries distinguish the geodynamic regimes of horizontal compression-stretching and shearing, for intraplate structures-vertical compression-stretching regimes [1]. The geodynamic activity intensity and forms of manifestation depend on the nature of the stressed state tensor. When designing and operating engineering structures, the manifestations of geodynamics on the earth's surface are significant, which can be conditionally divided into endogenous dynamics, including vibrational, folded and discontinuous movements of the Earth crust and exogenous dynamics in the form of landslides, creeps, avalanches, etc. [2].

The process of the relief formation in different historical times for the modern era is actual due to its progress at the borders of structural geoblocks. The boundaries of geoblocks, experiencing additional stresses of compression, stretching, shear, often coincide with the Earth crust faults. Movements in such places are manifested by slow "creep" processes or sharp splashes. The quantitative measure of movements has been widely studied with the advent of GPS-measuring technologies. Experience in the railways operation with

*Corresponding author: bikovanm@mail.ru 
substructure and superstructure strict registration of damage to constructions indicates their frequent occurrence at fault sites [3]. Unfortunately, the zoning of linear engineering objects lines on the basis of geotectonic activity is episodic.

The greatest attention is paid to the study of seismic geodynamics, causing maximum damage to nature and the creation of human hands. The territory seismic zoning maps [4] and the transport structures design principles under the conditions of seismic impacts [5], various approaches to constructive measures of structures protection. In different countries there are different approaches, both to the assessment of seismic hazard, and to the protection of engineering structures. In Russia, the emphasis is on the assessment of seismic hazard in points [6]. One can agree with the conclusions of the authors, but at the present stage, the main problem of the transition from scores to amplitude parameters or to peak accelerations is the lack of a sufficient volume of digital data on strong ( $M>6$ ) soil motions and buildings near the source zone $(\mathrm{D}<100 \mathrm{~km})$ in Russia. It is not clear what parameters should be operated on. In particular, the maximum (peak) acceleration as a parameter has its "minuses". For example, with the strongest earthquake in Mexico City, peak accelerations were only 1.8 $\mathrm{m} / \mathrm{s} 2$, and for weak earthquakes they reached 5-6 m/ s2. Even in the existing, very few strong movements databases in Russia, there are examples of records with a 10-15 times difference in peak accelerations at a fixed magnitude and epicentral distance. Therefore, at this stage, the use of points as a means of general seismic zoning is quite acceptable.

Another problem is the insufficient study of the danger of earthquakes with low intensity (less than 6 points on the MSK-64 scale) in the Earth crust fault zones. In the article [7] the character of displacements of a mountain massif with the Severomuisk tunnel is shown at a seismic event of 5.5 points on the MSK-64 scale (Fig. 1). The design characteristics of rocks, including fault zones, and the characteristics of a conventionally homogeneous rock massif are considered. Considering that in this region earthquake aggregations are recorded up to a dozen events with an intensity of 2-6 points per day, one should expect the accumulation of residual displacements at the fault boundaries.

(a)

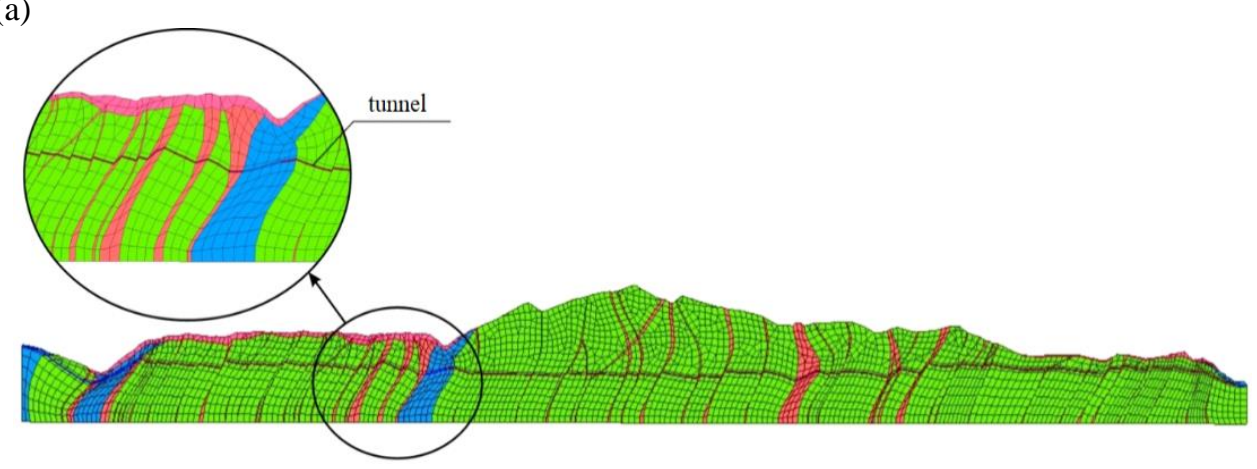

(b)

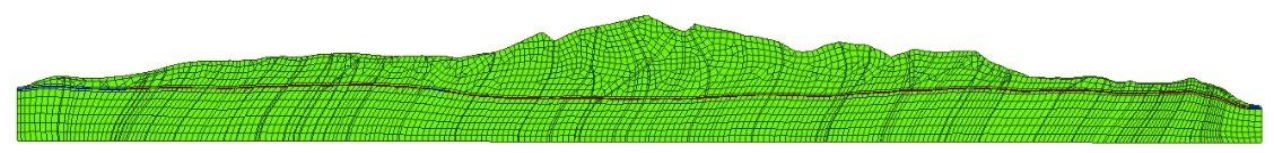

Fig. 1. The nature of displacements in the mountain massif with the tunnel under the seismic event 5.5 points: (a) heterogeneous mountain mass in the projected section; (b) conditionally homogeneous rock massif.

Waves on the earth's surface appear not only as a result of earthquakes, which are almost impossible to predict in the long term. The subject of the study with the development of the instrumental base were cyclical wave processes of the Earth crust, which have a small 
amplitude of displacements. The forecast of such waves is more likely with sufficient accumulation of quantitative data. It is obvious that wave geodynamics also poses danger to the boundary fault zones. Thus, from the author's analysis experience of the way failures on different sections of the Trans-Siberian Railway from st. Krasnoyarsk to the Ulan-Ude station deformations of the roadbed are recorded by dates with a temporary shift from west to east. The manifestation of forms of exo-geodynamics in the form of screes, landslides, creeps are an internal tectonic processes consequence complex, external gravitational forces and climatic phenomena. Arsenal of constructive protection of the way from such phenomena is quite wide.

As a result of all geodynamic forms manifestation in one or another quantitative measure, the properties of rocks, the structure, location and nature of the groundwater, gases, temperatures, electromagnetic fields manifestation change. Engineering facilities are associated with the Earth surface and undergoing altered impacts during operation, with a corresponding reactive response that reduces the load-carrying capacity of their structures.

\section{Geodynamic zoning of railway tracks}

One of the main geodynamic processes affecting the safety of transport facilities is the seismic hazard of the areas where they are located. Its undercounting often leads to catastrophic consequences (Figures 2,3). Undoubtedly, seismic hazard assessment maps are important for the transport facilities protection, but, with any manifestation of geodynamics, the fault zones boundaries are particularly sensitive. There are general faults on the tectonic maps of Russia , but there are no more dangerous developing active faults of a smaller scale.

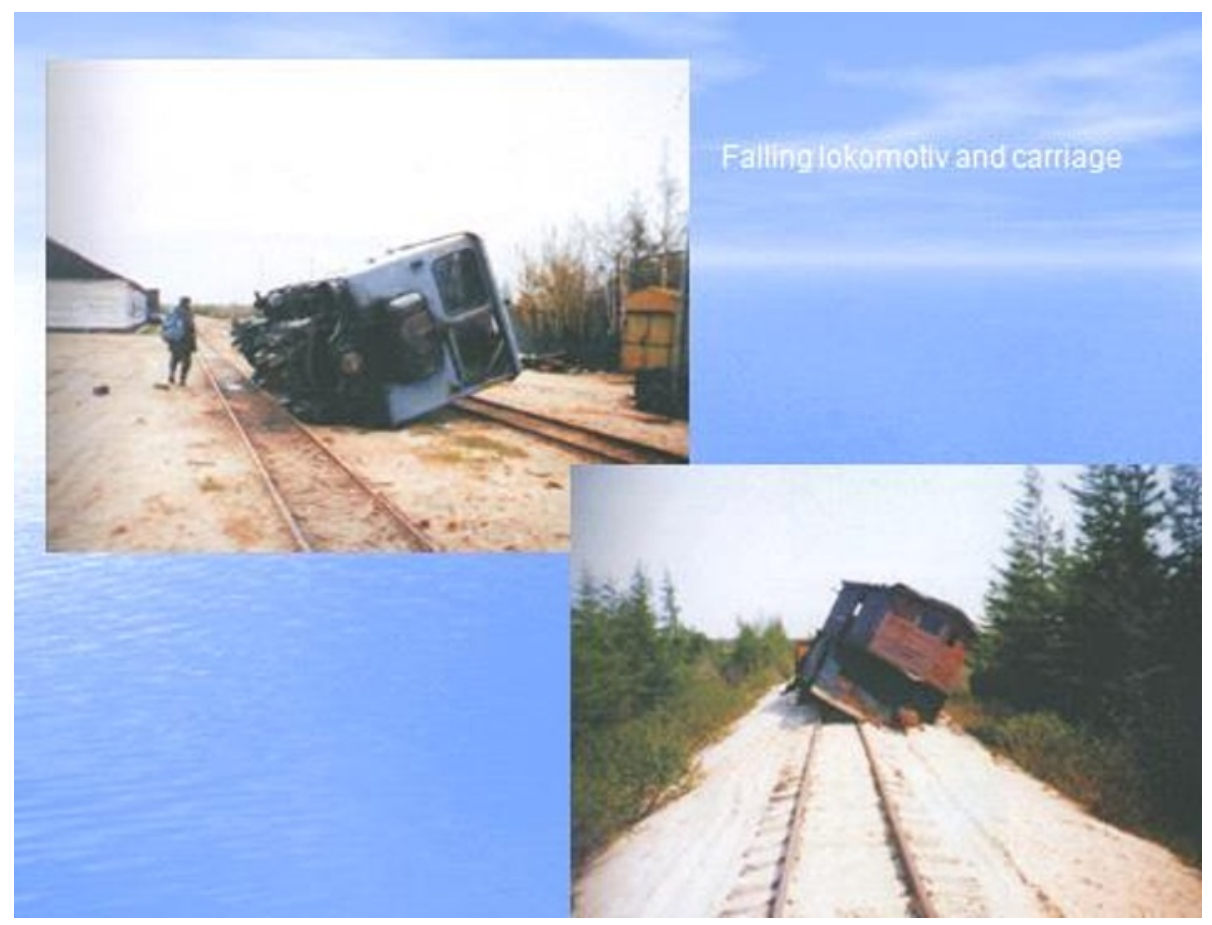

Fig. 2. The damage of railway at Sakhalin at the Neftegorsk earthquake of 1995 (photo by RM Semenov). 


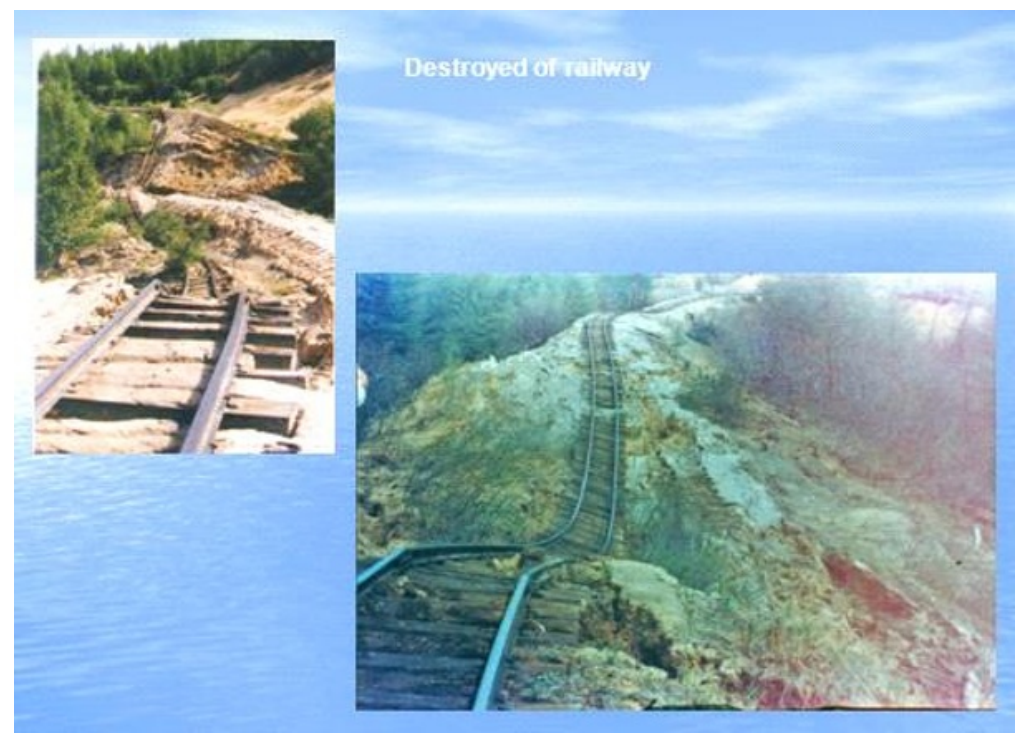

Fig. 3. The fall of the locomotive and the wagon at the Neftegorsk earthquake of 1995 at Sakhalin (photo by RM Semenov).

To identify such faults, there are various methods for analyzing signs of tectonic activity. With their involvement for the sections of the Trans-Siberian Railway (KrasnoyarskGorkhon Station) and the Baikal-Amur Main Line (Severobaykalsk-Hani Station) maps that tie faults and territories with active ascending downward movements of the Earth surface to kilometers of railways were developed [3]. The analysis of the statistical information about various substructure and superstructure construction failures manifestation in places of tectonic disturbances shows the significance of this factor when deciding on the support of the track during its operation. An important direction is the transition from the operational correction of track damages to the prediction of failures and the preventative constructive reinforcement of track sections at the fault boundaries.

\section{Monitoring and diagnostics of geodynamic safety transport facilities}

The operation of transport facilities is carried out for a long period, during which a systematic impact of functional and natural loads, including geodynamic phenomena, accumulation of fatigue in the materials of structures, violation of project contact links, changes in rigidity and load-bearing capacity of constructional elements. In such difficult conditions, there are facilities for both the long-running Trans-Siberian railway and modern transport lines, especially those operated in territories with geodynamic activity. The resource, laid at the structural design stage, is gradually decreasing.

The requirements for ensuring the overall technical safety of facilities are inextricably linked to a number of tasks that are solved at the stage of operation:

1) forecasting and control of external loads and impacts quantitative parameters;

2) control of structure technical parameters and assessment of the structure consumer properties compliance with regulatory criteria;

3) prompt restoration of consumer properties;

4) planning investment costs for cost-effective maintenance of transport facilities in the context of their safe operation. 
Existing monitoring systems, including monitoring of geodynamic safety, solve the first two problems $[7,8]$. The most effective are stationary automated monitoring systems that cover geodetic control using GPS and Glonass technologies, deformation and dynamic control of design parameters and a software package that processes the flow of information and solves the problems of assessing the consumer properties of structures with the formation of recommendations for operational and long-term measures to restore safe operating conditions of the structure.

Along with stationary efficient assistants, the mobile transport monitoring systems can be used for the maintenance of transport facilities, established for a short period [9]. With their help, it is possible to evaluate the conformity of the constructive system calculated and actual performance, to track the presence of internal defects, violation in comparison with the design prerequisites for the parameters of contact structural bonds, stiffness parameters.

The control of geodynamic factors is carried out by dynamic monitoring with the help of accelerometers and geodetic monitoring by means of GPS-receivers. Thus, during the operation of the automated monitoring system on the bridge at the Angara river, the bridge support displacements relative to each other were fixed .

To the present date, there are many different geological, geophysical, hydro-geological, geodetic and other data that can be used as predecessors of earthquakes [10,11]. Perhaps the most informative in this respect are hydrogeochemical studies. It was with them since the $60 \mathrm{~s}$ of the last century that large-scale searches of earthquake precursors began not only in the Soviet Union, but also in other countries. One of the main data was hydrogeochemical according to the successful prediction of the world-famous Haichensky earthquake in 1975 in north-eastern China [12].

In the past few years, the content of dissolved helium has been studied in the underground waters of the Southern Baikal region and in the deep water of the Baikal. The obtained data are analyzed with the manifestation of seismic activity. An investigation of the contents of helium shows that they have a pulsating character. Against the background of average values, both raised and lower concentrations are periodically observed. Such observations are also noted in other regions. As a rule, short-term deviations in the direction of increase or decrease from average values are characteristic for them. They are conditioned by various geological, geophysical, meteorological and other factors. But fluctuations in content associated with variations in the stress-strain state of the Earth crust just before the tremors are usually continued for a certain time, which can serve as a precursor to the time of the earthquake [13].

From the point of the geodynamic and other effects and changes in the design parameters of structural systems response evaluation, the development of a methodology for diagnosing and mathematical modeling of transport facilities strustures is of great importance.

An artificial structure, being a part of a transport system subjected to geodynamic influences, is a complex system connecting the properties of materials, structural elements with a certain geometry of dimensions, contact links between the elements. Each element is characterized by its own set of damages, which accumulate from combinations of different loads and impacts, taking into account changes in the properties of materials, static circuits of the elements. To compile a diagnostic map of such a structure, a large set of parameters is required, which can be obtained using various instrumentation systems and methods for diagnosing damage. The task of obtaining a reliable estimate of the technical state of constructive systems is inextricably linked with methods of collecting, processing and analyzing information, a wide variety of which is not always justified and cost-effective.

Therefore, in the organization of monitoring of individual parameters, it is advisable to diagnose the technical state from the level of analysis of constructive elements to a higher level - an artificial structure as a whole. As controllable parameters, both integral 
characteristics, for example, natural vibration frequencies, and certain invariant criteria, such as the ratio of stresses in the upper and lower booms of a bent beam, can be adopted.

At the initial stage, there should be created a mathematical model of the structure, sufficiently reflecting the actual work of all the structural elements. Modern software finite element systems allow to solve this problem - as the experience of numerous bridge structures tests shows, finite elemental spatial models allow obtaining computational results that coincide with the actual stress-strain state of the construction fixed during the tests. The design coefficient is close to unity $(1.00 \pm 0.05)$.

The next stage of the work is the analysis of possible risks. In practice, a significant number of potential failures scenarios can be drawn up in the risk assessment. Therefore, when assessing the criticality of risks for macroelements or the structure as a whole, the qualitatively rank of the scenarios with their reflection in risk matrices is advisable. The quantitative definition then concentrates on scenarios that give higher levels of risk. The calculation of the risks criticality consists of two consecutive estimates:

- assessment of the hazard implementation consequence severity: from insignificant (1 point) to catastrophic (4 points);

- an estimation of object macroelements critical failures probability: insignificant probability (1 point), high probability (4 points).

The multiplication of the hazard consequence severity scores and the failure probability gives a quantitative characteristic for determining the level of danger. Geodynamic processes can lead to catastrophic or significant consequences with medium and high probability, i.e. give the highest level of danger.

An example of various extraordinary situations simulation is shown in Figure 4 (red color indicates the elements, the voltages in which can exceed the calculated resistances, blue close to the calculated resistance). The model of the railway farm is $86 \mathrm{~m}$ long in the Midas / Civil program package. With the use of beam elements, the elements of the main trusses, the carriageway, upper, lower and transverse connections are constructed, the material of the structure is specified and the support parts are modeled by setting the boundary conditions. In accordance with the current regulations, the calculation of structures is made taking into account unfavorable combinations of loads.

In addition, an analysis of possible risks has been performed using the methodology outlined above and the following most likely simulations have been modeled:

- wedging of the support part;

- support roll (by $\alpha=1^{\circ}$ );

- the cross-sectional area reduction of one of the elements as a result of the corrosion or fatigue damage development.

The analysis of the obtained data allows to isolate the elements on which it is necessary to install the sensors of the monitoring system (in the figure 4 it is marked with red circles). It should be noted that to ensure full control requires a large number of equipped monitoring points, respectively, significant material costs, so it is necessary to develop special solutions for cost optimization: use the symmetry of structural elements; allocate the most informative nodes; to determine how the damage of some elements will affect the stress-strain state of others, and so on.

The adequacy of the developed mathematical model and the possibility of using it to compose a forecast of changes in the technical state must be confirmed by tests.

The main result of the monitoring system is not so much fixing the onset of an emergency situation, but rather predicting a change in state for risk assessment and taking preventive measures 
a)

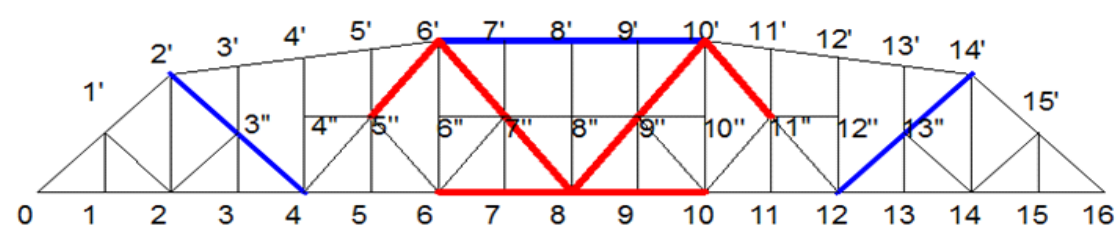

b)
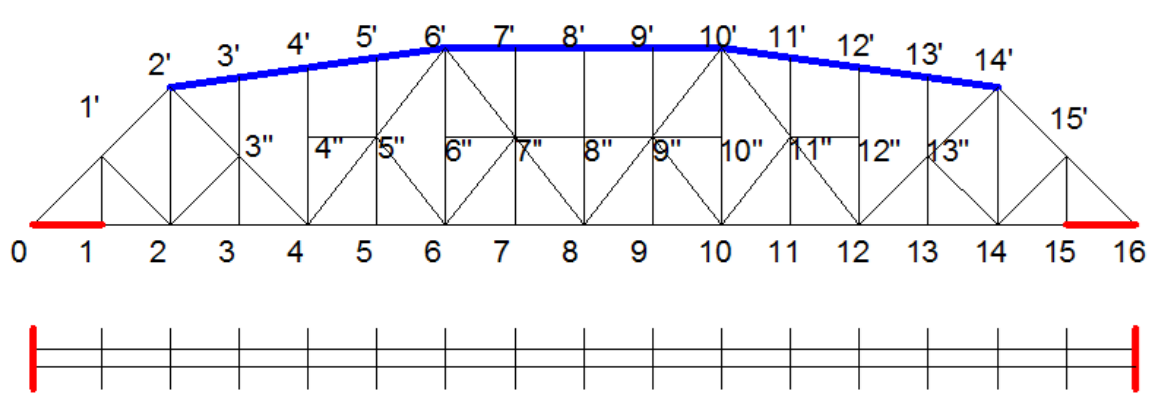

c)

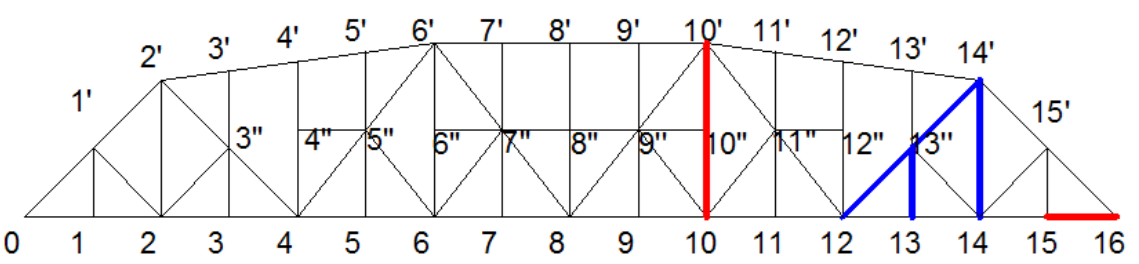

d)

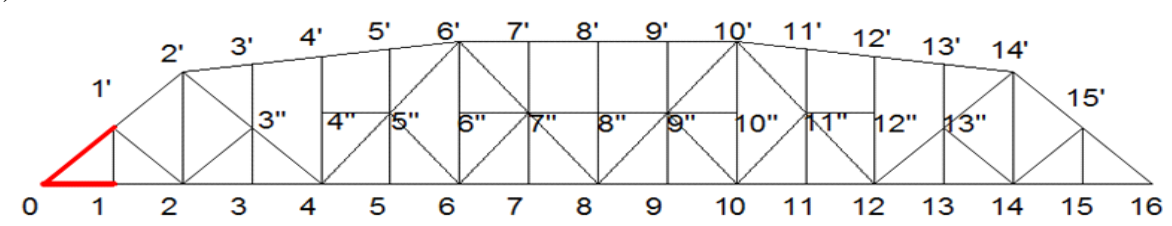

e)
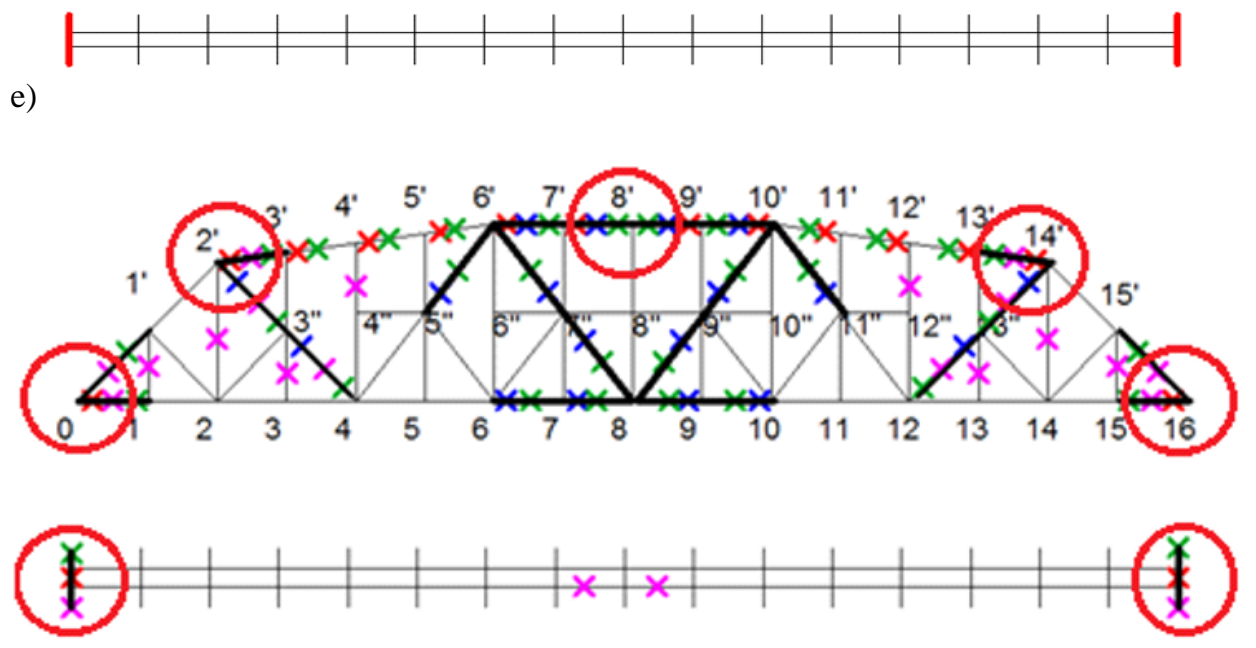

Fig. 4. The results of the calculation of the span structure: a) minimum classes for load-lifting; b) minimum reserves at a regular combination of loads; c) jamming of the support parts; d) roll of the intermediate support; e) the final scheme for the designation of monitoring points. 


\section{Conclusion}

1. Ensuring the geodynamic safety of operated long transport structures requires a systematic approach, both to the study of geodynamic actions, and to the protection of man-made structures.

2. Attention is focused on the fact that the least studied are the effects of fracture tectonics, although with all known forms of geodynamic manifestation, the largest damages of extended transport structures are recorded at fault boundaries of the Earth crust blocks.

3. An important step towards ensuring geodynamic safety is the zoning of long-distance transport routes on the basis of tectonic activity signs, primarily on the location of active faults on the routes. This will make it possible to intensify the observation system on the TCP.

4. When monitoring, evaluating, forecasting and restoring the consumer properties of extended transportation facilities, monitoring systems that collect information on geodynamic and other impacts and reactive responses of structural elements provide irreplaceable assistance. The development of effective and optimal diagnostic methods for monitoring systems with a view to predicting changes in the status of ETF, risk assessment and taking preventive measures is topical.

\section{References}

1. N.A. Logachev, S.I. Sherman, K.G. Levy, Geodynamic regimes and factors of geodynamic activity of the lithosphere, Geodynamics of the inland continental mountain areas (Science, Novosibirsk, 1990)

2. N.M. Bykova, Seismic resistant construction 4, 17-22 (2004)

3. N.M. Bykova, Transport buildings on active geostructures. Systems approach technologies (Science, Novosibirsk, 2008)

4. Russian Standard SP 14.13330.2011

5. Russian Standard SP 268.1325800.2016

6. E.N. Kurbatsky, G.E. Mazur, V.L. Mondrus, Academia. Architecture and construction 2, 95 - 102 (2017)

7. D.A. Zainagabdinov, N.M. Bykova, Science: Internet-journal 5, http://naukovedenie.ru/PDF/13KO514.pdf (2014)

8. T.M. Baranov, N.M. Bykova, Transport construction 4, 17-20 (2013)

9. N.M. Bykova, T.M. Baranov, E.O. Tolstikov, Internet Journal Transport facilities 2-4, http://t-s.today/issues/vol2-no4.html (2015)

10. I. Rikitake, Tectonophysics 54, 293-309 (1979)

11. G.A. Sobolev, Fundamentals of earthquake prediction (Nauka, Moscow, 1993)

12. Haichengearthquake 1975.2.4 (Shenyong, 1982)

13. R.M. Semenov, V.V. Kashkovsky, M.N. Lopatin, Geodynamics \& Tectonophysics 9(1), 165-175 (2018) 